\title{
As classes sociais na sociedade do espetáculo: o olhar dos torcedores de futebol
}

\author{
Clara M. S. M. de Freitas
}

https://doi.org/10.5628/rpcd.05.03.329

\author{
Universidade de Pernambuco \\ Escola Superior de Educação Física \\ Brasil
}

\section{RESUMO}

Esta investigação objetivou fazer uma análise a respeito do significado do desporto/futebol nas classes sociais. As categorias analisadas nesta investigação tomaram por base as contradições e os avanços peculiares da nossa sociedade, onde se afirma ser o futebol um instrumento/meio que faz a sociedade pernambucana experimentar a quase igualdade social. Participaram deste estudo, de cunho descritivo, 234 torcedores dos clubes Náutico Capibaribe, Santa Cruz, Sport e Tecnologia de Componentes Automotivos. Assim, para se obter as informações acerca da realidade investigada, utilizou-se a entrevista aberta estruturada, realizada durante os jogos do Campeonato Pernambucano de Futebol. A análise do material discursivo foi efetuada buscando os elementos de natureza quanti-qualitativo indicados na análise de conteúdo. Os resultados apresentados sobre a questão relacionada com a forte torcida pelo futebol apontaram que a torcida é um espetáculo de partilha cultural e revela cidadania, visto que está validada a paixão do torcedor pelo futebol. Afirma-se, pois, ser o futebol um dos campos mais ricos da paixão e da revelação humana. Portanto, com todas as contradições e lutas de classes que envolvem o desporto/futebol nos mais distintos campos sociais, culturais e econômicos, ele se apresenta como uma opção para a prática do exercício da cidadania na busca por uma sociedade moderna, onde as relações sociais são amparadas pela socialização dialógica e das emoções, com o significado de reduzir a distância existente nas estruturas sociais de classe de hoje.

Palavras-chave: significado do desporto, classes sociais, torcedores, socialização das emoções.

\author{
ABSTRACT \\ Social classes in society's performance-show: \\ the view of football fans
}

This paper sets out to analyze the significance of soccer within the context of social classes. The categories examined in this investigation were based on the contradictions and specific advances of our society, in which we state that football, by producing a complex show governed by simple rules, is a tool or means that enables Pernambuco society to experience a virtual social equality. Two hundred and thirty-four supporters of four clubs (Náutico Capibaribe, Santa Cruz, Sport and Tecnologia de Componentes Automotivos) participated in the present study, which is descriptive in nature. Thus, in order to obtain the data on the situation investigated, an open structured interview was used, that was conducted during the games of the Pernambuco Football Championship. The analysis of the discursive material was made by eliciting the quantitative and qualitative elements indicated in the content analysis. The results presented on the strong enthusiasm for football showed that this enthusiasm is a spectacle of social sharing and reveals a sense of citizenship, since the fans' passion for football is somewhat validated. Football is thus shown to be one of the richest areas of human passion and manifestation. Therefore, for all the contradictions and class struggles involving the sport of football in the most diverse social, cultural and economic fields; this sport presents itself as an option for the exercise of citizenship in the quest for a modern society in which social relations are supported by the socialization of dialogue and feelings, the significance of which is the narrowing of the existing gap between the social classes in today's society.

Key Words: significance of sport, social classes, fans, socialization of feelings. 


\section{INTRODUÇÃO}

O foco principal da presente investigação reside na tentativa de se compreender o significado social do desporto enquanto um fenômeno histórico e social, que pode separar, distinguir ou reunir as classes. No plano teórico, busca-se ancoragem nas mais variadas concepções sobre o desporto, dentro das quais o primeiro conceito -chave trabalhado foi o de cultura.

Essa matriz possibilitou a análise do modo de pensar sobre o desporto, como criador de um estilo de vida própria. Sustenta-se na formulação teórica que o desporto é cultura em todos os seus aspectos, porque é uma instituição relativamente autônoma que cria uma rede piramidal de encontros.

A revisão teórica revelou que tem havido um esforço considerável no sentido de explicar o significado do desporto enquanto fenômeno cultural. Por outro lado, têm sido relativamente escassos os estudos concluídos no tocante ao desporto e às classes sociais; entretanto alguns estudiosos têm demonstrado interesse e, dentre eles, pode-se mencionar a dedicação pela investigação nos estudos de Bouet (2), Bourdieu (3), Brohm (5), Defrance (8), Elias (9), Jeu (11), Lüschen (13), Pociello (15). Neste particular, uma contribuição inestimável foi fornecida pelos estudos feitos sob os influxos da teoria sociológica do desporto enquanto fenômeno social total. Estas análises mostram: a) ser função do desporto a integração do indivíduo na sociedade; b) ser o desporto uma diversão com um forte componente de ludicidade; c) em alguns momentos, o desporto serve à manutenção da estabilização social. Coerentes com estas conclusões, os teóricos do desporto julgam que não existem fronteiras bem definidas entre as ciências sócio-antropológicas e o desporto, que clarifiquem e delimitem determinados conceitos.

Seguramente, a análise do futebol se apresenta nas sociedades contemporâneas com inúmeras dimensões sobre o significado social dessa realidade percebida. O notável no desporto é que ele cresceu como um fenômeno que atravessou a era industrial, sobreviveu ao início da era pós-industrial e continua assumindo papéis demandados pela sociedade.

\section{TRAJETÓRIA METODOLÓGICA}

Assim, o ponto de partida desta investigação não foi uma hipótese formal derivada da teoria sociológica, mas um problema definido a partir da intuição imediata e prática da realidade que ser viria como campo de obser vação: o estádio de futebol. Constatou-se que a Região Metropolitana do Recife representada pelos clubes: Náutico Capibaribe, Santa Cruz, Sport e Tecnologia de Componentes Automotivos, representava, em relação à problemática proposta, um universo estratégico para a análise social sobre o desporto. O caminho seguiu três etapas: inicialmente a pesquisa bibliográfica se fez orientada na discussão do significado do desporto em suas possíveis vinculações com as classes sociais. Uma segunda etapa, o trabalho de campo propriamente dito. Assim, para se obter as informações acerca da realidade investigada (Jogos realizados no Campeonato Pernambucano de Futebol), utilizou-se a entrevista aberta, estruturada, com 234 (duzentos e trinta e quatro) torcedores, homens e mulheres, que assistiam ao espetáculo. Os atores sociais foram entrevistados antes da partida $e$ localizados por um processo aleatório nos estádios de futebol, segundo sua posição espacial: arquibancadas, cadeiras e camarotes. Todo este processo teve a duração de seis meses, aproximadamente.

Numa última etapa, fundamental, tratou-se da leitura e análise das entrevistas. O desenho metodológico pode ser resumido da seguinte maneira: numa primeira instância descreveu-se o conteúdo das variáveis ou núcleos temáticos tais como: cultura, tradição, identidade, ludicidade, relações de proximidade, gosto, emoção, conflito, derrota, civilidade, sociabilidade e classe social, partindo de análises individuais. Sua definição foi possível a partir de expressões verbalizadas pelos entrevistados, na forma em que foram emitidas, ou ainda por uma retradução semântica ou teórica das mesmas. Numa segunda instância, buscou-se acessar os elementos comuns. Neste aspecto, as frases típicas ou núcleos temáticos foram analisados segundo a freqüência.

\section{UM DISCURSO DO UNIVERSO DOS TORCEDORES À LUZ DO GOSTO PELO FUTEBOL NA SOCIEDADE DO ESPETÁCULO}

$\mathrm{Na}$ decomposição dos discursos foram agrupadas todas as categorias encontradas nos estratos inferiores, médios e superiores, formando uma totalidade. Assim, esta análise buscou completar o caminho percorrido e mostrar o significado social do fenômeno desporto nas classes. 
Diante disto, uma pergunta óbvia então aparece: você gosta do futebol e por que? A análise que aqui se ensaia, trata, pois, de compreender as funções sociais do futebol sobre o imaginário do torcedor, considerando que se fazem presentes categorias que são elementos significativos de identificação tais como a emoção, a saúde e a cultura. Não há nenhum país em que não seja uma das distrações preferidas, ao mesmo tempo em que se apresenta como o espetáculo favorito das massas. Enquanto espetáculo de massas versus elite, convém recordar que no processo de industrialização, no século XIX, a atividade desportiva, de um modo geral, era absor vida pela classe economicamente mais poderosa e com maior quantidade de tempo livre. Nesta perspectiva, seria difícil não reconhecer os méritos de Bourdieu (4) quando aprecia a teoria do amadorismo na dimensão da filosofia aristocrática do desporto enquanto uma prática tão desinteressada semelhante à prática artística, porém mais adequada que a arte, para afirmação das virtudes viris dos futuros líderes. Assim, o desporto é concebido como divertimento de coragem, de formação de caráter, bem como inculca nos participantes a vontade de vencer e triunfar dentro das regras de um verdadeiro fair play.

Obser vou-se que as classes sociais constituíram entre si uma hierarquia, tanto ao nível da participação nas atividades sociais, quanto ao nível das necessidades características de cada classe. Configura-se, pois, a indicação de um quadro analítico do sistema social das classes no desporto. Pode-se mesmo afirmar à luz dos estudos eliasianos, (9) que, em todos os discursos dos torcedores, o futebol apresenta-se como um fenômeno que provoca o mimetismo, enquanto atividade de lazer, no qual produz uma excitação agradável e exerce uma função de acabar com a rotina o que, na perspectiva social, se constitui num dado universal.

Trazendo à refle xão as concepções dos torcedores sobre o significado do futebol, a idéia que permeia é a de que os torcedores do futebol são realmente criaturas apaixonadas sem limites pelo jogo. Aliás, as paixões não devem ter limites senão perdem o sabor da atraente irracionalidade. O confronto é saudável, sobretudo se o profissionalismo prevalece, impondo se como a bandeira maior da competição. O gol, já se sabe, pontifica o grande objetivo do futebol, os empates são sempre decepcionantes e não induzem a grandes celebrações festivas. Portanto, "os jogos de futebol se caracterizam pelo dionisíaco que deles brota. A bola no pé reverencia os delírios, os sonhos, as fantasias de um povo abafado nos seus anseios sociais" (16, p. 2). Verificou-se, na análise dos resultados, que o futebol tem sido um fator de aproximação entre as regiões $e$ nações. Vínculos de estima e de camaradagem estreitam-se facilmente entre os fieis a um mesmo jogo, por mais cruel que tenha sido a luta e seja qual for o resultado. O futebol pernambucano é, na concepção dos atores sociais, um elemento democratizante de união entre distintas classes.

De acordo com as categorias expostas, pode-se falar de mobilidade, integração, socialização, sociabilidade e civilidade desde que sejam consideradas como um conjunto de relações sociais estabelecidas entre desportistas/torcedores. A discussão recai primeiramente, nos aspectos da integração, grupos, socialização e sociabilidade, onde a maioria dos torcedores tende a ir ao campo de futebol na companhia da família e/ou de amigos. Assim sendo, num determinado momento de desafio, os torcedores tendem a ficar ligados a pequenos grupos situados ao seu redor, independente da classe social. Num nível de maior abstração eles estão ligados ao clube ou, ainda, ligados ao jogo em si. Neste sentido pode-se inferir que o futebol induz as pessoas a fazerem parte de uma comunidade de gostos onde os significados, as práticas e as obrigações são compartilhadas. Vestem a camisa (12, p. 192).

No tocante aos aspectos relacionados com a sociabilidade, civilidade, onde os laços (informais) de amizade e de união entre as distintas classes são fortalecidos pelos princípios da igualdade e identidade entre os torcedores/espectadores, cabe ressaltar que os indivíduos no momento da disputa fazem parte do mesmo mundo - o mundo futebolístico. Este vínculo de estima, camaradagem e união entre as classes constitui uma expressão social característica da civilidade. Bento (1, p. 96) revelou que o desporto foi sempre "local de exercitação da urbanidade, civilidade, da conviviabilidade e do encontro dos homens: consigo mesmo e com os outros, isto é, com a natureza pessoal e com a natureza social". A idéia agora é a de lembrar que a derrota no futebol é entendida como perda dos sonhos para milhares de 
torcedores adeptos do jogo, principalmente para as classes economicamente inferiores, que se apresentam carentes de alimentos, moradia, emprego e dignidade e que esperam pelo menos ser felizes com aquilo que é a sua maior paixão: o futebol. Retoma-se aqui a idéia de Halbwachs citado por Gurvitch (10) sobre a memória coletiva (práticas sociais), adicionando-se a categoria devaneio/fantasia da qual ele define como sendo o momento que fica entre a memória e o sonho. Portanto, o devaneio passa a ser entendido como um momento de lazer dando oportunidade para que a mente delire. Assim, cada vez mais os torcedores são conduzidos a procurar não um só prazer, mas um conjunto de prazeres de acordo com as preferências de classe.

Ainda no conte xto desta análise, a derrota representa a morte coletiva, simbolizada pela derrota dos atletas em campo. E, sem dúvida, o nosso tempo prefere a imagem à coisa, a cópia ao original, a representação à realidade, a aparência ao ser. O que é sagrado para o atleta não é senão a ilusão, mas o que é profano é a verdade. Melhor, o sagrado cresce a seus olhos, à medida que decresce a verdade e que a ilusão aumenta, de modo que, para ele, o cúmulo da ilusão é também o cúmulo do sagrado, ressalta Debord (7). Neste raciocínio, fica explícito que a atividade desportiva é, sobretudo, um comportamento social que, como tal, cobra significado, dependendo do local em que se realiza e das pautas das relações sociais que o regulam.

Por último, no conte xto desta análise, não se pode deixar de evocar os conhecimentos de Costa (6, p.14), que acredita que o desporto pode constituir "um meio excelente para se estudar e melhor compreender a cultura do povo que o pratica e da sociedade onde ele funciona, e estender esse conhecimento aos outros povos da comunidade humana que tem, na prática desportiva, um meio de se encontrar". Numa época histórica em que a humanidade sonha com projetos de universalidade, esse papel cultural do desporto não é, de forma alguma, desprovido de significação humana. Em síntese, pode-se afirmar que o futebol brasileiro com seus movimentos surpreendentes e mágicos vai fornecendo as tintas para mesclar a vida, compondo uma tela com raízes dos mais variados modos culturais.

\section{ANÁLISE SÓCIO-ANTROPOLÓGICA DO DESPORTO/FUTEBOL ENQUANTO CULTURA POPULAR/CULTURA DE MASSA}

Continua-se com a análise sobre a cultura popular/cultura de massa, a partir da leitura apurada das falas dos torcedores pernambucanos. Aqui, a intenção é analisar a cultura como fator histórico, onde as atividades têm lugar espontaneamente e não visam, nem um valor universal, nem um caráter de obrigatoriedade. Cabe situar as manifestações da cultura popular/cultura de massa através da questão básica: como você explica a forte torcida pelo futebol? Com sua linguagem própria, cada torcedor expressa de forma clara e direta o seu entendimento e percepção. A análise das falas concentra-se, pois, no que se torna expressivo salientar : que o torcedor/espectador percebe que a nossa torcida é sempre a nossa melhor imagem. A torcida é um espetáculo de partilha cultural e revela cidadania. Está validado que a paixão pelo futebol, se para algumas pessoas pode parecer de menor importância, não o é seguramente para a maioria dos pernambucanos.

Examina-se de perto as categorias mais representativas indicadas pelos torcedores. As análises dos temas apoiam-se em noções complementares, pois buscam estabelecer relações entre sociabilidade $x$ tradição nas distintas classes, enquanto elementoschave na construção deste estudo. Esta discussão permite entender a sociabilidade como a capacidade humana de estabelecer redes, individuais ou coletivas, fazendo circular informações que exprimem interesses, gostos e paixões. Note-se de passagem, a nível destes elementos apontados, que este paradigma está em consonância com um dos princípios enunciados por Simmel (17) com o qual a sociabilidade é afastada da referência material. A sua identificação remete para a compreensão da sociabilidade enquanto forma lúdica da socialização. Assim, pode-se inferir que o elemento do prazer é o sentimento agradável vivido pelo fato de se estar na companhia dos outros sem qualquer obrigação ou dever para com eles, para além daqueles que se tem voluntariamente. Um exame da sociabilidade revela que nunca será demais pôr em evidência os mecanismos de mobilização da coletividade (independente da classe social) de que dispõe o futebol, enquanto espaço sociocultural. Touraine $(18$, p. 14) vai mais além quando diz que 
as sociedades que se comovem com o futebol não são, nem as mais ricas, nem as mais justas, "mas são aquelas em que a ordem institucional é mais transgredida, às vezes para pior, mas, mais freqüentemente para melhor, para a vitalidade, a resistência e a esperança de um povo". Chega-se ao final deste caminhar, na necessidade de repensar o sentido do desporto, especificamente do futebol, enquanto fenômeno de massas, de modo a que seja possível evitar a sua deterioração. O tratamento que Murad (14, p. 108) consagra a esta questão é interessante: o "desporto é uma organização social do lúdico, e toda a sociedade elege uma modalidade que o caracteriza". E o Brasil escolheu o futebol, que traduz muito bem a nossa cultura.

\section{CONCLUSÃO}

Foi traçado um esboço dos aspectos sócio -antropológico e cultural do desporto/futebol. Mas é necessário que não sejam concebidos como impermeáveis. Neste cenário, o estudo revelou que nos estratos superiores, o futebol é lazer, é divertimento, é sair das coisas sérias da vida, é sair da rotina. Entretanto, nos estratos inferiores, é mais do que isto, é razão de viver, é tudo que tenho. É verdade que estas premissas mostram que o futebol desperta emoção, tensão e excitação agradável, e de forma singular para todas as classes. Entretanto, a maneira de expressar o prazer enquanto sentido de vida assume características distintas nos estratos sociais; entrando aí o aspecto da sensibilidade, do gesto, da idade e do gosto, que é o que faz a diferença, é o que marca a distinção. Em outro registro, foi verificado que o futebol tem sido um fator de aproximação entre as regiões e nações. Vínculos de estima e de camaradagem estreitam-se facilmente entre os fieis a um mesmo jogo, por mais cruel que tenha sido a luta e seja qual for o resultado. O futebol pernambucano é, na concepção dos atores sociais, um elemento democratizante de união entre distintas classes.

Foi possível constatar que é sobretudo nos discursos entre as classes populares que o futebol exerce maiores influências enquanto perspectiva de vida. Por se encontrarem em uma categoria social quase sem atrativos, as pessoas dão as costas à estética nacional e vão em busca da estética do futebol, onde passam a usar da sua liberdade para expressar os seus anseios, os seus gostos. Entre as classes médias a preocupação maior reside nos aspectos relacionados com a utilização do desporto para encobrir os problemas sociais e também como alternativa de trabalho para a população mais carente. Nas classes privilegiadas, que dispõem do luxo e da liberdade absoluta das suas fantasias, o futebol é só distração, passar o tempo, é lazer. Entretanto, foi salientado que o futebol apresenta-se como um dos mecanismos de retirar as crianças da marginalidade e da droga. Reforça-se que este aspecto foi lembrado por quase todos os entrevistados, independentemente da classe social.

O importante no futebol não é o fato de atrair milhões de espectadores aos jogos, mas que esses grandes momentos são o ápice da pirâmide, cuja base é feita de grupos de crianças e jovens que batem bola no pátio de uma escola ou de um terreno baldio. Acredita-se que o futuro do Brasil está na rua com as crianças. Hoje, são poucas as atividades sociais que garantem uma continuidade tão grande, desde a base até o topo e que, portanto, permitem uma identificação tão forte. Trata-se de um movimento que vem de baixo para cima, ou seja, nasce nas classes populares e aparece fora das instituições e das hierarquias.

\section{CORRESPONDÊNCIA}

\section{Clara Maria S. M. de Freitas}

Rua Amazonas, 223

Apartamento 802 - Boa Viagem

51011-020 - Recife, Pernambuco

Brasil

clarasilvestre@uol.com.br 


\section{REFERÊNCIAS}

1. Bento, J. (1998). Desporto e Humanismo. O campo do possível. Rio de Janeiro: Editora da Universidade do Estado do Rio de Janeiro.

2. Bouet, M. (1968). Signification du sport. Paris: Ed. Universitaires.

3. Bourdieu, P. (1994). O poder simbólico. Lisboa: DIFEL.

4. Bourdieu, P. (1996). Razões Práticas. Sobre a teoria da ação. São Paulo: Papirus Editora.

5. Brohm, J. M. Bourdieu, P. Dunning, E. (1993). Deporte y Clase Social. In: Materiales de Sociologia del Deporte. Madrid: Las Ediciones de La Piqueta.

6. Costa, A. (1997). À Volta do Estádio. Porto: Campo das Letras Editores S. A.

7. Debord, G. (1991). A sociedade do espectáculo. Lisboa: Mobilis In mobile.

8. Defrance, J. (1995). Sociologie du Sport. Paris: Éditions La Découverte.

9. Elias, N. (1992). Em busca da excitação. Lisboa: DIFEL.

10. Gurvitch, G. (1982). As classes sociais. São Paulo: Global Editora.

11. Jeu, B (1988). Análisis del deporte. Barcelona: Ediciones Bellaterra.

12. Lash, S. (1997). A reflexividade e seus duplos: estrutura, comunidade. São Paulo: Editora UNESP

13. Lüschen, G. Weis, K. (1979) . Sociologia del deporte. Miñón S.A.

14. Murad, M. (1996). Dos pés à cabeça: elementos básicos para uma sociologia do futebol. Rio de Janeiro: Irradiação Cultural Ltda.

15. Pociello, C. Bourdieu. P. (1981). Sports et société. Paris: Vigot.

16. Quintas F. (1998). Bola na trave. Jornal do Comércio. Recife: 26 de Jul. p.2.

17. Simmel, G. (1993). Filosofia do amor. São Paulo: Martins Fontes.

18. Touraine, A. (1998). Esporte cria relação de proximidade. Folha de São Paulo. São Paulo: 21 de Jun. p. 14. 